\title{
NEW APPROACH FOR RISKS RANKING OF THE INITIAL INNOVATION IDEA USING DATA ENVELOPMENT ANALYSIS
}

\author{
Milena KIROVA (D* \\ Department of Management and Business Development, Faculty of Business and Management, \\ University of Ruse, 8 Studentska str., 7017 Ruse, Bulgaria \\ *E-mail: mkirova@uni-ruse.bg
}

\begin{abstract}
Purpose - this paper presents the application of Data Envelopment Analysis (DEA) for risks ranking in a graphical form at the initial stages of the innovation process, by using the innovation potential as an output parameter of DEA.
\end{abstract}

Research methodology - an example of the potential change of a given innovation under the influence of certain risk is presented. The data for the risk assessment and the reduction of the potential after the expression of the risks are given. On the bases of this data, a graph for the boundaries of the risk effectiveness is constructed, according to DEA models.

Findings - DEA is applicable for the risk ranking, including for risks with equal effectiveness evaluations.

Research limitations - the approach is applied to risks which are initially selected for ranking. The other types of risks are not considered, and they need separate research attention.

Practical implications - the new approach may be used in the initial stages of product and process innovation.

Originality/Value - the innovation potential is used as an output parameter in the DEA to graphically rank the risk of the initial innovation applications.

Keywords: Data Envelopment Analysis, risk, ranking, innovation potential, innovation evaluation.

JEL Classification: C61, C67, D24, D81, M11.

Conference topic: Contemporary Financial Management.

\section{Nomenclature}

DEA Data Envelopment Analysis.

DMU Decision Making Unit.

$\triangle \mathrm{P} \quad$ Magnitude of reducing the potential of innovation.

P_risk Probability of occurrence of risk.

VRS Variable Return to Scale.

CRS Constant Return to Scale.

TE $_{\text {CRS }}$ Technical effectiveness at a constant rate of return.

VTE $_{\text {VRS }}$ Technical effectiveness at a variable rate of return.

SE Scale efficiency.

\section{Introduction}

\section{Background}

Generating ideas and shaping them into innovations is a crucial moment in business. Normally, this stage of innovation development is accompanied by optimism, which is useful. It maintains the impetus for creativity and entrepreneurship, gaining strength and courage for quick action, aspiration for leadership, rapid and early acquisition of markets (Pencheva, 2018; Yordanova, 2018). However, excessive optimism is dangerous and unacceptable (Nedyalkov, 2014). It can lead to erroneous evaluations of external conditions, the innovator's in-house capabilities, to cause a slowdown in development or a failure of the idea (Alexandrova, 2015). 
In order to avoid negative developments, the management must have the tools to study and evaluate the business environment, and also the company's own knowledge and experience (Lambovska, 2018; Papazov \& Mihaylova, 2015). It is requested to provide the decision makers with true information about the realization of the idea as an innovation, including the risks that the innovator must deal with (Stoycheva \& Antonova, 2018). At this stage of development, the possibilities for evaluations are too limited (Vilys, Jakubavičius, \& Žemaitis, 2015). Therefore, there should be no underestimate of supposed and probabilistic evaluations to minimize uncertainties, including risks, too close to the realities boundaries (Magruk, 2016). The risks in the innovation process in a specific organization may be different at its stages. The most important is the market risk and the factors which influence it - main characteristics of contracts, trading conditions; the position taken in the contract, the complexity of the contract (Martinkute-Kauliene, 2014). A risk portfolio can be set up by identifications and risk evaluations.

The opportunities for innovation to achieve a positive economic result are determined by assessing the potential of the innovation, and on its basis ranking the risks for its applications (Kirova, 2009). From these evaluations, the parameters of the input and output indicators of the idea can be formed.

\section{Purpose}

This paper presents the application of Data Envelopment Analysis (DEA) for the risk ranking in a graphical form, at the initial stages of the innovation process, by using the innovation potential as an output parameter of DEA. This novel approach can answer the question about which risks need to be monitored and managed, and the impact of their ranking on the innovation potential being assessed.

\section{Literature review on DEA methods}

There are many methods for risk ranking like risk assessment, comparative risk assessment, risk ratio, risk scoring, risk matrix, flow charts, multi-criteria decision analysis, etc. (Fels-Klerx et al., 2017). They are generally part of a broader group of methods for decision making and evaluation of effectiveness including for innovations, where DEA is considered to be very effective in solving business problems, because its effectiveness can be analyzed and quantified (Velasquez \& Hester, 2013), which is its greatest advantage in comparison with the other methods.

DEA is an analytical tool used for business effectiveness evaluations in many areas (Hadad, Friedman, \& Israeli, 2005; Wang \& Lu, 2015; Yao, Han, \& Luo, 2010; Zhu, 2009). DEA is also known to be able to rank different models (Jablonksy, 2016) evaluate risks of the units surveyed (Aldamak \& Zolfaghari, 2017; Chang, Chung, Sun, \& Yang, 2012), and analytically rank risks (Sheludko \& Kirova, 2018). Characteristic which makes it a very good tool for risk ranking is it's capable of handling both one input and one output parameters, and many parameters of one object. This is convenient for risk classification and visualization by graphical representation of the inputs - output and the significance of the risks. DEA is a comparative tool and it uses data collected through other tools.

DEA has different models suitable for different applications, with the basic model in the core of the analysis, and the others being its modifications (Cooper, Seifold, \& Tone, 1999). The current research uses two DEA models: CRS with constant return to scale, and VRS - with a variable return to scale. They are used in their basic form with one input and one output parameter because they can be easily presented in a graphic form. Because these two models do not allow risk ranking, another DEA model for the "effectiveness dependence on the scale" is used, which combined with the first two is called the "3E" approach (Cooper et al., 1999).

The novelty of this research is the use of the innovation potential as an output parameter of DEA for risk ranking using graphical representation.

The capabilities of DEA with the requirements for risk ranking and the choice of approach from the many known developments and additions of DEA are shown in Table 1.

According to a study of the qualities of DEA (Smith, 1997) presented in Table 1, it is clear that the method meets the requirements for risk assessment entirely in Section A. In Section B, which lists deficiencies of the DEA, the comparison points to small differences between DEA's capabilities and requirements in risk ranking. In each case, ways to overcome the emerging weaknesses are possible. In Section C of Table 1, the DEA requirements for the data to be fit for analysis by comparing efficiencies are entirely satisfied when presenting risks for the same analysis.

With the examples of presenting the capabilities of the method and the comparison in Table 1, it is proven that DEA is applicable to properly and reasonably ranking innovation risks. The importance of this opportunity is underlined by the fact that DEA can be applied at the earliest moments of the innovation process. At this stage, there is not enough economic, technological, market and other data, and it is necessary to decide on the realization of the innovation on the basis of risk assessment. 
Table 1. DEA Capabilities and Risk Ranking Requirements (source: compiled by the author)

\begin{tabular}{|c|c|c|}
\hline № & Qualities of DEA & Requirements for Risk Ranking \\
\hline \multicolumn{3}{|c|}{ 1. Key Features of DEA (Smith, 1997) } \\
\hline 1.1 & DEA uses multi-factor features in object comparison (DMU) & $\begin{array}{l}\text { The risks are of a complex nature. They are evaluated } \\
\text { through a set of criteria. }\end{array}$ \\
\hline 1.2 & $\begin{array}{l}\text { DEA performs comparisons of effectiveness by comparing } \\
\text { the input and output parameters of the units being evaluated. }\end{array}$ & $\begin{array}{l}\text { Risk management is characterized by the magnitude of } \\
\text { initial characteristics (inputs) and their change and } \\
\text { values after impacting them, or their impact on certain } \\
\text { objects with given initial characteristics. }\end{array}$ \\
\hline 1.3 & $\begin{array}{l}\text { The DMU application results consist of assessing the } \\
\text { effectiveness of each unit involved in the benchmarking of } \\
\text { the weight combination, or the available unit parameters. The } \\
\text { results lying on the boundaries of effectiveness are effective } \\
\text { units with evaluation of a unit. The rest are less effective. }\end{array}$ & $\begin{array}{l}\text { The risks are compared by the set of their } \\
\text { characteristics, indicating which is more significant } \\
\text { than the others by one or more indicators. A threshold } \\
\text { of significance is determined for the choice of the risks } \\
\text { to be monitored and influenced. }\end{array}$ \\
\hline 1.4 & $\begin{array}{l}\text { DEA uses parameters and initial data collected through other } \\
\text { methods and tools. Their list depends on the available } \\
\text { options. }\end{array}$ & $\begin{array}{l}\text { Various methods and approaches are used to assess the } \\
\text { risks based on certain parameters that can characterize } \\
\text { them. }\end{array}$ \\
\hline \multicolumn{3}{|c|}{ 2. DEA deficiencies (Smith, 1997) } \\
\hline 2.1 & $\begin{array}{l}\text { DEA builds the effectiveness boundary based on currently } \\
\text { available DMUs and their results, without taking into account } \\
\text { whether technological capabilities suggest better options. The } \\
\text { benchmark is the achievements of certain objects at the time } \\
\text { of the survey. }\end{array}$ & $\begin{array}{l}\text { Risk assessments shall use the estimates for each } \\
\text { present risk that are probable and determine the } \\
\text { outcome. }\end{array}$ \\
\hline 2.2 & $\begin{array}{l}\text { DEA does not comply with parameter priorities (Shen et al., } \\
\text { 2011). It is possible that a particular parameter will result in a } \\
\text { high estimate of the DMU under certain consideration, while } \\
\text { there is another parameter that would lead to a lower score. }\end{array}$ & $\begin{array}{l}\text { Such a situation may exist in the risk assessments, but } \\
\text { in these cases it remains the responsibility of the } \\
\text { analyst, who may carry on a further assessment of the } \\
\text { specific risk and adjust the initial assessment by re- } \\
\text { thinking the analysis. }\end{array}$ \\
\hline 2.3 & $\begin{array}{l}\text { Some evaluations may underestimate or overestimate the unit } \\
\text { under study, especially at the boundary of effectiveness. }\end{array}$ & $\begin{array}{l}\text { Such weakness can exist for the risks. It can be } \\
\text { removed by further checking the selected units or } \\
\text { increasing the number of units surveyed, where } \\
\text { available. }\end{array}$ \\
\hline 2.4 & $\begin{array}{l}\text { DEA is an optimization method with its peculiar } \\
\text { shortcomings. Its individual models indicate the local } \\
\text { optimum of the task. }\end{array}$ & $\begin{array}{l}\text { Risk assessments cannot be applied to results with a } \\
\text { continuous score. Such may only apply to theoretical } \\
\text { principle assumptions. Such weakness can be achieved } \\
\text { in some methods, which is compensated by additional } \\
\text { graphical representation of dependencies. }\end{array}$ \\
\hline 2.5 & $\begin{array}{l}\text { DEA computes hypothetical DMU using a weighted } \\
\text { combination of real DMUs, without being clear whether such } \\
\text { a combination may exist under the specific conditions during } \\
\text { the research. }\end{array}$ & $\begin{array}{l}\text { The evaluation are probabilistic for the risks. Such } \\
\text { assumptions are possible. They can be avoided by } \\
\text { selecting an appropriate model for the different types } \\
\text { of scale of performance, which is in the analyst's } \\
\text { capabilities and his/her specific knowledge about DEA } \\
\text { and risk management. }\end{array}$ \\
\hline 2.6 & $\begin{array}{l}\text { DEA gives a unit rating ( } 100 \% \text { effectiveness) to all units } \\
\text { lying on the effectiveness boundary curve. In fact, they differ, } \\
\text { but this is not the case in the classic method. }\end{array}$ & $\begin{array}{l}\text { When assessing the risks, there is also a similar } \\
\text { possibility, but this does not reduce the quality that } \\
\text { aims to identify the most effective risks. Avoiding it is } \\
\text { possible with additional assessment through various } \\
\text { DEA modifications or other methods. }\end{array}$ \\
\hline 2.7 & $\begin{array}{l}\text { DEA estimates the performance of individual units. Despite } \\
\text { the fact that those on the boundary curve get the same rating - } \\
100 \% \text { effectiveness, it is almost impossible to cooperate to } \\
\text { move the border to more effective values, especially if } \\
\text { heterogeneous entities are compared. Improving the } \\
\text { achievements of an object will change the performance limit } \\
\text { and cause a new curve configuration as well as eventual new } \\
\text { DMU positioning. }\end{array}$ & $\begin{array}{l}\text { When assessing the risks, an analogous situation is } \\
\text { possible, especially if the risks are generated from } \\
\text { different sources and are very different in nature. } \\
\text { Better performance is possible if it comes to } \\
\text { innovation with risks with certain dependencies and } \\
\text { better management options. Provided there are such } \\
\text { opportunities, this is an advantage over the quality of } \\
\text { the study. }\end{array}$ \\
\hline
\end{tabular}


End of Table 1

\begin{tabular}{|c|c|c|}
\hline № & Qualities of DEA & Requirements for Risk Ranking \\
\hline \multicolumn{3}{|c|}{ 3. Requirements for the necessary data } \\
\hline 3.1 & DEA uses digital data & The risks are characterized by digital parameters \\
\hline 3.2 & DEA requires the data to be classified as input and output & $\begin{array}{l}\text { Risks are characterized by initial (input) data and } \\
\text { subsequent occurrence (output) data. }\end{array}$ \\
\hline 3.3 & $\begin{array}{l}\text { The minimum number of parameters characterizing the units } \\
\text { studied is at least two. }\end{array}$ & $\begin{array}{l}\text { The risk characteristics may be two or more } \\
\text { parameters. }\end{array}$ \\
\hline 3.4 & For comparing objects, DEA requires that they be at least two. & $\begin{array}{l}\text { Any innovation can be accompanied by two or } \\
\text { more risks. }\end{array}$ \\
\hline 3.5 & $\begin{array}{l}\text { Various authors point to observing certain ratios between DMU } \\
\text { number and number of parameters. } \\
\text { Boussofiane recommends that the minimum number of elements } \\
\text { to be tested, be equal to the number of input parameters } \\
\text { multiplied by the number of baseline parameters (Boussofiane, } \\
\text { Dyson \& Thanassoulis, 1991); } \\
\text { Golany and Roll recommend that the number of observations be } \\
\text { at least twice as large as the total number of input and output } \\
\text { parameters (Golany \& Roll, 1989); } \\
\text { According to Bowlin the number of observed elements is at least } \\
\text { three times greater than the total number of input and output } \\
\text { parameters (Bowlin, 1998); } \\
\text { Dyson suggests the following formula to determine the recom- } \\
\text { mended number of parameters: (number of input parameters * } \\
\text { number of output parameters) * } 2 \text { (Dyson et al., 2001); } \\
\text { To obtain a larger share of ineffective objects in DEA results, it is } \\
\text { necessary to increase the number of investigated objects or to } \\
\text { reduce the number of input or output parameters considered } \\
\text { (Avkiran, 2006). }\end{array}$ & All ratios are possible in the risks. \\
\hline
\end{tabular}

\section{Procedures}

\subsection{DEA application for risk ranking in the innovation process}

An example of the changing of the potential of innovation under the influence of certain risks is presented. The current evaluations at the time of the research are used. The choice to look at the potential of the innovation is dictated by the fact that the research is done at an early stage when no other data is available. In addition, its assessment is also made on the basis of the external conditions and in-house state of the innovator, as well as the risks. This is a prerequisite for up-to-date data at the time of the survey.

Table 2. Initial Data and Risk Ranking Results with Equal VRS Values and “3E” Approach” (source: compiled by the author)

\begin{tabular}{|c|c|c|c|c|c|}
\hline Risk & $\begin{array}{l}\text { Input parameter - } \\
\text { probability of } \\
\text { occurrence of a risk, } \\
\text { P_risk }\end{array}$ & $\begin{array}{l}\text { Output parameter - the } \\
\text { magnitude of reducing the } \\
\text { potential of innovation } \Delta \mathrm{P}\end{array}$ & $\begin{array}{l}\text { DEA assessment } \\
\text { based on input } \\
\text { model }\end{array}$ & $\begin{array}{l}\text { Evaluation by Entry } \\
\text { Oriented Model } \\
\text { under "3E" } \\
\text { approach }\end{array}$ & $\begin{array}{l}\text { Ranking by Entry- } \\
\text { Oriented Model } \\
\text { under "3E } \\
\text { approach" }\end{array}$ \\
\hline A & 0.25 & 0.05 & 1 & 0,227 & V \\
\hline B & 0.27 & 0.15 & 1 & 0,659 & III \\
\hline $\mathrm{C}$ & 0.35 & 0.3 & 1 & 1 & I \\
\hline $\mathrm{D}$ & 0.5 & 0.35 & 1 & 0,84 & II \\
\hline $\mathrm{E}$ & 0.7 & 0.4 & 1 & 0,657 & IV \\
\hline
\end{tabular}

Table 2 sets out the data for assessing the risks to be managed and reducing the potential of innovation after eventual exposure to the risks involved. On the basis of this data, the graph for the risk limit is constructed and shown in Figure 1. The effectiveness of the risks has to be understood in a way that a higher risk assessment leads to a greater reduction of the potential $\Delta \mathrm{P}$ - the difference in the assessment of the potential before and after the occurrence of a risky event. The assessment of the potential change from a given risk is done in accordance with the risk potential method (Kirova, 2009). 
Innovation, with a maximum innovativeness rating of 0.9 points and a potential of 0.8 points on a 10 -point scale of 0.1 to 1 according to the methodology for assessing the potential of innovation (Kirova, 2009) is considered. Consideration is given to a risk, assessed in the view of intense competition, that a competitor product is likely to emerge on the market with an unknown solution to the same level or higher than that of the innovation under consideration. As a consequence, the innovation of the assessed innovation declines with three levels of similar solutions not known to matching known solutions, and innovation declines from 0.9 to 0.6 , that is, with three levels reflecting respectively a fall in the potential.

As stated by many authors who developed DEA additions, the units that are on the effectiveness boundary are of equal value - a unit or 100\% effectiveness (Cooper et al., 1999). Despite the same maximum rating, the DMUs - in this case, the risks - are not the same. An approach is proposed that ranks DMU on the effectiveness boundary, in this case ranking the effectiveness of pre-selected risks that are most effective and should be included in the monitoring and management list. Table 2 presents the risks and assessments of potential changes in their eventuality.

The risks $\mathrm{P}$ _risk with one parameter along the $\mathrm{X}$-axis and the change of the $\Delta \mathrm{P}$ potential along the $\mathrm{Y}$-axis are graphically plotted on Figure 1 . The broken bold line is the effectiveness boundary on which lie the most effective DMUs according to DEA assessment at variable return. The OC thin line is the effectiveness boundary at constant return on the scale. Due to the VRS convexity, according to DEA theory (Cooper et al., 1999), it coincides with the VRS performance curve at only one point. This point presents DMU of interest with the highest effectiveness in both cases - with a constant and variable return. The remaining DMUs on the VRS, despite their equal maximum DEA ranking, do not match and do not lie on the OS line, which is the CRS effectiveness boundary.

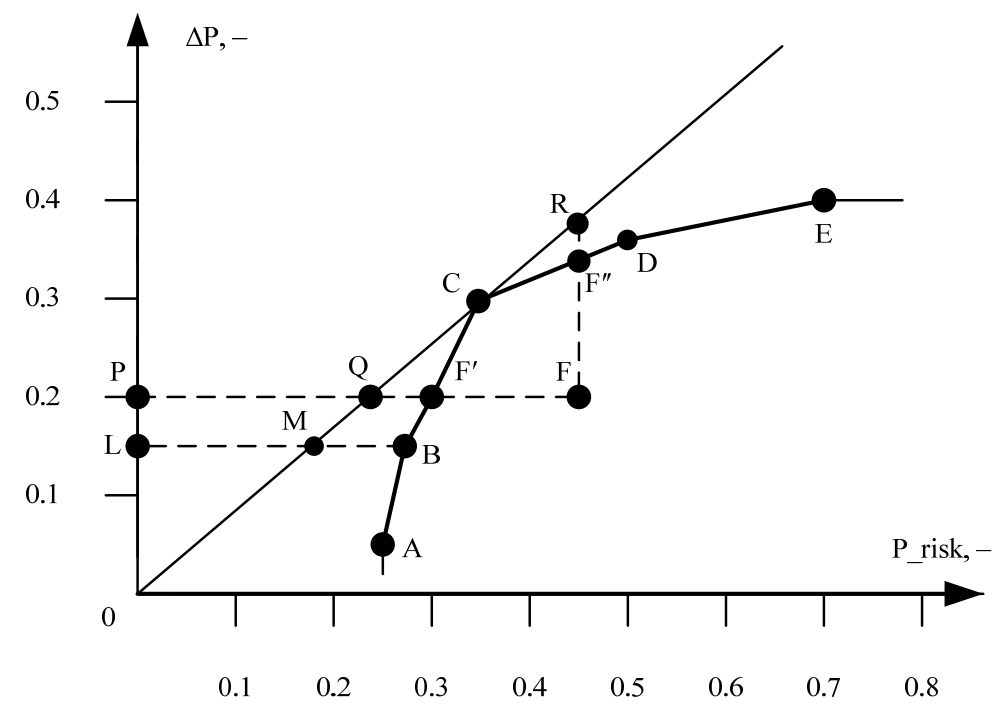

Figure 1. Graph of the effectiveness CRS, VRS and line segments, determining SE (source:compiled by the author)

The increase of the input parameter at constant return on scale leads to a proportional increase of the output linear dependence. Under variable pay-off, the increase in the output is not proportional to the increase in input. The characterization of this disproportionality is represented by the concept of "scale efficiency". DEA develops and determines the dependencies of the three dimensions:

- Technical effectiveness at a constant rate of return TE CRS $_{-}$LM segment in Figure 1;

- Technical effectiveness at a variable rate of return VTEVRS - LB segment on Figure 1;

- The efficiency of the SE scale.

In accordance with the above explanation and the graph on Figure 1, the following dependencies are determined (Cooper et al., 1999).

$$
S E=\frac{T E_{C R S}}{V T E_{V R S}} \leq 1,
$$

where: $T E_{C R S}$ - technical effectiveness at constant rate of return; $V T E_{V R S}$ - technical effectiveness at variable rate of return; $S E-$ scale efficiency.

The effectiveness of the SE scale actually shows how far apart are the effectiveness at constant and variable returns. This magnitude is different for each point of the VRS performance limit, respectively for each DMU (risk) lying at the VRS boundary. When capturing the sizes of the relevant sections of the graphs and determining their relationships, the risks are ranked by SE. For the sake of clarity, the approach developed by DEA will be referred to as the "3E" approach (the approach of the three effectiveness). 
An input-oriented model of the graph on Figure 1 for $\mathrm{SE}$ will produce for point B LM: $\mathrm{LB}=0.659$. Similarly for the other points: $\mathrm{A}=0.2 ; \mathrm{C}=1 ; \mathrm{D}=0.84 ; \mathrm{E}=0.657$, where $\mathrm{C}>\mathrm{D}>\mathrm{B}>\mathrm{E}>\mathrm{A}$.

The results are shown in Table 2, where they are ranked. Point $\mathrm{F}$ is an ineffective DMU (risk) and does not fall into the list of observed risks. If, at a certain point, F receives F ' or F" value - input or output-oriented model - this risk must be ranked in the presented "3E" approach, as well as monitored and managed. At the same time, it will trigger a new positioning and risk ranking. The same approach can be applied to an originally oriented model with equal success.

In the example under consideration, the risks lying on the boundary effectiveness are ranked, with the variable return of the scale. In the classic version of the DEA, they have the same effectiveness evaluation and cannot be ranked. DEA tools - CRS, VRS and SE, which measure the effectiveness, are used. The correctness of how to use them should be checked. The correctness of their choice as a criterion for ranking of the risks effectiveness is also checked.

The effectiveness boundary at the steady return from the CRS scale expresses the ratio of the output quantity to the input and the dependence is linear. The DMUs that lie on it have maximum effectiveness of $100 \%$. This boundary is the line originating from the beginning of the coordinate system. The angle between it and the X-axis depends on the effectiveness of the compared processes (risks). With higher effective processes, this angle and the steepness of the beam are larger. DMU that lie simultaneously on the VRS and CRS boundaries coincide with the ideal theoretical boundary with the highest effectiveness. The CRS boundary is determined by one of the DMU units but applies to all considered in the given study. Therefore, the CRS boundary is desired. This gives reason to use it as a base measure of effectiveness. When dealing with risk ranking through DEA, the risks are selected using the usual methods to identify risks and assess their impact on the potential of the innovation in question in any way. DEA allows this because it does not use its own data collection system. When the "3E" approach is being tried, for the risks output parameter is selected the difference in the value of the potential $\Delta \mathrm{P}$, before and after the expression of any of the risks. This parameter is defined in the manner described in the publication of this topic (Kirova, 2009). The CRS line as the baseline effectiveness measure cannot be defined by a known method because the risk data does not indicate any dependencies that would define such a boundary. This does not hinder the implementation of the "3E" approach for the presented risk ranking with one input and one output. The CRS boundary is built unmistakably as a line coming out of the coordinate beginning and passing through DMU, to which the VRS graph is pre-built, based on the parameters of the risks that will be ranked. There may be cases where CRS can pass through more than one DMU without crossing the VRS graph. The latter condition is obligatory in the theory of application of DEA of the enveloping curves. It can be applied seamlessly and accurately to any number of DMU posing risks to the ranks. The said circumstance is specific to the DEA's application for risk ranking and its observance is not an obstacle to this. It is only a condition for using a well-designed and widely popular approach, such as DEA for risk ranking.

The VRS boundary of the variable returns of the scale, expresses the actual values of the DMU effectiveness, lying on it. The basic version of DEA gives these DMUs an equal effectiveness rating of $100 \%$. These DMUs are practically not the same, but due to the above condition, they cannot be ranked. Based on the effective measurement and previous statement, it can be assumed that the closer a DMU to the CRS boundary is, the closer it is to $100 \%$ effectiveness. This judgment gives reason to include the distance of the various DMUs from the CRS in determining their effectiveness, as the DMUs present the risks with the relevant parameters.

The value of scale return - SE effectiveness, includes the CRS and VRS dimensions for each individual DMU. Where the conditions for measuring specific dependencies are established, the effectiveness of these DMUs under the "3E" approach can be determined, regardless of their DEA assessment. The tried approach is a continuation of the basic version of DEA.

When DMU presents production processes or standalone business entities, analyzing their performance is important. It, however, depends on a variety of conditions and internal opportunities for each individual firm. Those who are not subject to company leadership are considered. Effectiveness in these cases does not entirely depend on company management.

When only one DMU of the investigators lies at CRS and VRS at the same time, it is the one with a maximum effectiveness value of $100 \%$. The rest, regardless of the DEA rating, should have lower effectiveness. The " $3 E$ " approach solves this issue by using SE and ranking risks.

There could be cases where there are more than one DMU lying on CRS and VRS at the same time. The " $3 E$ " approach cannot detect a difference in their performance to rank them since the attitude of the efficiencies for them is the same - a unit. They remain in the ranking with this rating as equal to maximum efficiency.

\section{Results of approving the risk ranking approach by applying DEA}

The use of the CRS boundary, which represents a proportional input/output dependency, requires clarification of a theoretical separate case beyond that, in which the CRS boundary has a single common point with the VRS boundary. The single common point between the two boundaries is due to the fact that the VRS boundary is convex. The CRS boundary does not intersect it, but can only be tangent at one point - that of the DMU, which has for both a unit value (100\% effectiveness). This DMU has the highest CRS and VRS effectiveness at the same time. All other DMUs are at 
a different distance from the CRS boundary. This distance is a sufficient condition for ranking, as the example examined. In manufacturing processes, this situation is most common. It is due to the fact that the change of the scale is accompanied by disproportionate concomitant phenomena. For example, when increasing the amount of the used ore (input parameter) for a metallurgical installation, the output parameter - pure metal, is not proportional to the input. The reasons for this are disproportionate losses at different capacities, varying degrees of intensity and load. The same situation is present in the energy processes, the chemical industry and others. They pursue the optimum result - the highest percentage of the output product at a different input parameter level. This point is precisely the one at the two borders. It is specific to each process and to each aggregate. It is the same with risks. The DMUs (the risks) lying on both borders should be given the greatest attention.

\section{Conclusions}

DEA is applicable for risk ranking, including those risks with the same effectiveness estimates, derived from the application of the basic model.

When presenting risks through the DMU, it is usually a portfolio ranking of risks for one innovation. In this case, the ranking is no less important. All the more so, it is at an early stage of the innovation process, when it must be clear with what risks the innovator is involved. Their reflection on the potential of innovation is crucial for further work on innovation realization and diffusion. In this sense, risk ranking is essential.

The example under consideration confirms the conclusion from the comparison of the qualities of the DEA and the requirements for risk assessment, and in particular for its classification, namely that DEA is applicable for the risk ranking through the use of the "3E" approach at a common point between CRS and VRS. At more than one common point between the two effectiveness boundaries, the VRS limit is interrupted. The presentation of the dependencies between CRS and VRS is also interrupted. DMU effectiveness has a value determined by CRS - $100 \%$ effectiveness.

The use of data collected and obtained through the use of other methods allows the combination of DEA with them - a quality that makes the method widely applicable, including risk ranking.

The "3E" approach has the following advantages that make it practical for risk assessment, comparing with another method, including the analytical ones:

- Clear, accessible and easy to understand. The graphical representation creates accurate visualization and minimizes the abstract elements of other modes of presentation;

- Secure, reproducible without errors for all risks in one study and in various studies;

- Provides clear results comparable to risk assessments, which is a prerequisite for true ranking;

- It does not distort the results and ensures comparability and compatibility with the results of other DEA models;

-For the application of the presented approach, it is necessary only to select properly and classify the data from the point of view of the input and output consideration;

- The use of output data does not require special processing;

- Errors in partial results are acceptable and do not change the final result.

The example used in the paper shows the possibility of combining DEA with an assessment of the potential of innovation with clear and accurate results.

Combining the qualities of DEA with the assessment of innovation potential allows assessment of the opportunities and risks of innovation at an early stage of their development, without the need for costly investment research and design.

\section{Funding}

This work is supported by the fund "Scientific Research" of the University of Ruse through project 19-BM-01 "Research of the digitalization processes in the organization's management systems". The project leader is Assoc. Prof. Milena Kirova, PhD.

\section{Disclosure statement}

I declare that I do not have any competing financial, professional, or personal interests from other parties, concerning this publication.

\section{References}

Aldamak, A., \& Zolfaghari, S. (2017). Review of efficiency ranking methods in data envelopment analysis. Measurement, 106, 161-172. https://doi.org/10.1016/j.measurement.2017.04.028 
Alexandrova, M. (2015). Risk factors in IT outsourcing partnerships: Vendors, perspective. Global Business Review, 16(5), 747759. https://doi.org/10.1177/09721509155914277

Avkiran, N. (2006). Productivity analysis in the service sector with Data envelopment analysis. SSRN Electronic Journal, 4-23. https://doi.org/10.2139/ssrn.2627576

Boussofiane, A., Dyson, R., \& Thanassoulis, E. (1991). Applied data envelopment analysis. European Journal of Operational Research, 52(1), 1-15. https://doi:10.1016/0377-2217(91)90331-0

Bowlin, W. F. (1998). Measuring performance: an introduction to data envelopment analysis (DEA). The Journal of Cost Analysis, 15(2), 3-27. https://doi:10.1080/08823871.1998.104623188

Chang, D. S., Chung, J. H., Sun, K. L., \& Yang, F. C. (2012). A novel approach for evaluating the risk of health care failure modes. Journal of Medical Systems, 36(6), 3967-3974. https://doi:10.1007/s10916-012-9868-5

Cooper, W., Seifold, L., \& Tone, K. (1999). Data Envelopment Analysis: A comprehensive text with models, applications, references and DEA-solver software. Kluwer Academic Publishers. Boston/Dordrecht/London.

Dyson, R., Allen, R., Camanho, A., Podinovski, V., Sarrico, C., \& Shale, E. (2001). Pitfalls and protocols in DEA. European Journal of Operational Research, 132(2), 245-259. https://doi:10.1016/s0377-2217(00)00149-11

Fels-Klerx, H. J., Asselt, E. D., Raley, M., Poulsen, M., Korsgaard, H., Bredsdorff, L., \& Frewer, L. J. (2017). Critical review of methods for risk ranking of food-related hazards, based on risks for human health. Critical Reviews in Food Science and Nutrition, 58(2), 178-193. https://doi:10.1080/10408398.2016.1141165

Golany, B., \& Roll, Y. (1989). An application procedure for DEA. Omega, 17(3), 237-250. https://doi:10.1016/03050483(89)90029-7

Hadad, Y., Friedman, L., \& Israeli, A. A. (2005). Evaluating hotel advertisements efficiency using Data Envelopment Analysis. Journal of Business Economics and Management, 6(3), 145-153. https://doi:10.3846/16111699.2005.9636103

Jablonsky, J. (2016). Ranking models in Data Envelopment Analysis. Business Trends, 6(4), 36-42.

Kirova, M. (2009). Methods for evaluation of the innovation potential. Journal of Entrepreneurship and Innovation, 1, 30-40.

Lambovska, M. (2018). Control on lecturing teams at a higher school. Strategies for Policy in Science and Education, 26(1), 54-74.

Magruk, A. (2016). Uncertainty in the sphere of the industry 4.0 - potential areas to research. Business, Management and Education, 14(2), 275-291. https://doi:10.3846/bme.2016.332

Martinkutè-Kaulienè, R. (2014). Risk Factors in Derivatives Markets. Entrepreneurial Business and Economics Review, 2(4), 7183. https://doi.org/10.15678/EBER.2014.020405

Nedyalkov, A. (2014). Staffing issues of information systems from the viewpoint of operations management of services. SocioBrains, 1, 155-164.

Papazov, E., \& Mihaylova, L. (2015). Approaches to strategy-driven sectoral competition analysis of business organizations. In 15th International Conference Perspectives of Business and Entrepreneurship Development (pp. 80-89). Brno, Czech Republic.

Pencheva, M. (2018). Methodological aspects of examination of leadership and organizational culture influence on knowledge conversion in public administration. Proceedings of the International Conference on Business Excellence, 12(1), 760-771. https://doi.org/10.2478/picbe-2018-0068

Sheludko, I., \& Kirova, M. (2018). Modification of data envelopment analysis for risk ranking in international business. 18-th International Scientific Conference Globalization and Its Socio-Economic Consequences, Zilina, Slovakia, 2789-2796.

Shen, Y., Hermans, E., Ruan, D., Wets, G., Brijs, T., \& Vanhoof, K. (2011). A generalized multiple layer data envelopment analysis model for hierarchical structure assessment: A case study in road safety performance evaluation. Expert Systems with Applications, 38(12), 15262-15272. https://doi:10.1016/j.eswa.2011.05.073

Smith, P. (1997). Model misspecification in Data Envelopment Analysis. Annals of Operations Research, 73(0), $233-252$. https://doi.org/10.1023/A:1018981212364

Stoycheva, B., \& Antonova, D. (2018). Investigating factor interactions in formalizing the process of developing new products. Serbian Journal of Management, 13(1), 173-184. https://doi.org/10.5937/sjm13-16409

Velasquez, M., \& Hester, P. (2013). An analysis of multi-criteria decision making methods. International Journal of Operations Research, 10(2), 56-66.

Vilys, M., Jakubavičius, A., \& Žemaitis, E. (2015). Impact assessment of public innovation support in European economic area. Business, Management, and Education, 13(2), 203-219. https://doi:10.3846/bme.2015.299

Wang, M., \& Lu, S. (2015). Information technology and risk factors for evaluating the banking industry in taiwan: an application of a value Chain DEA. Journal of Business Economics and Management, 16(5), 901-915. https://doi:10.3846/16111699.2014.976255

Yao, S., Han, Z., \& Luo, D. (2010). Performance of the Chinese insurance industry under economic reforms. Cheltenham: Edward Elgar. https://doi.org/10.4337/9781849807258

Yordanova, D. (2018). University-industry cooperation for the encouragement of graduating employability - a methodology for evaluation. Proceedings of the International Conference on Business Excellence, 12(1), 1048-1058. https://doi:10.2478/picbe2018-0094

Zhu, J. (2009). Quantitative models for performance evaluation and benchmarking-Data envelopment analysis with spreadsheets. Retrieved from https://www.springer.com/us/book/9783319066462 